\title{
REDESAIN KOMPOR BIOMASSA TIPE DOWNDRAFT SYSTEM CONTINUE DENGAN MENGGUNAKAN BAHAN SEKAM PADI
}

\author{
Thambarriyaldi Tuina Effendi ${ }^{1)}$, Romi Djafar ${ }^{2)}$, Sjahril Botutihe ${ }^{2)}$ \\ ${ }^{1)}$ Mahasiswa Politeknik Gorontalo, Kampus Puncak Desa Panggulo Bone Bolango \\ ${ }^{2)}$ Tim Pengajar pada Program Studi Mesin dan Peralatan Pertanian, Politeknik Gorontalo
}

\begin{abstract}
ABSTRAK
Kompor gasifikasi adalah salah satu teknologi pemanfaatan biomassa untuk keperluan memasak pada sektor rumah tangga. Gasifikasi biomassa merupakan suatu proses dekomposisi termal dari bahan-bahan organik melalui pemberian sejumlah panas dengan suplai oksigen terbatas untuk menghasilkan synthesis gases yang terdiri dari $\mathrm{CO}, \mathrm{H} 2, \mathrm{CH} 4$ (selanjutnya disebut dengan syn-gas) sebagai produk utama dan sejumlah kecil arang karbon dan abu sebagai produk ikutan. Tujuan utama saya dalam menciptakan inovasi teknologi yang sedang berkembang saat ini supaya hasil yang didapat lebih efektif dan berkualitas. Metode penelitian yang digunakan dalam penelitian adalah metode eksperimen, diawali pengamatan dilapangan (observasi) kemudian dari sumber studi pustaka selanjutnya diaplikasikan dalam satu model dimensi dengan perencanaaan yang diwujudkan dalam satu bentuk nyata berupa prototipe kompor biomassa tipe downdraft system continue. Komsumsi bahan bakar berturut-turut didapat sebesar $0.00012 ; 0.00028$; dan $0.00050 \mathrm{~kg} / \mathrm{hr}$. Total operating time dari kompor masing-masing sebesar 14; 16 dan 18 menit Power input berdasarkan hasil analisis masing-masing sebesar 0.00037 ; 0.00088 ; dan $0.00154 \mathrm{~kW}$. Berdasarkan hasil analisis didapatkan power output terendah sebesar $7.3 ; 17.1$ dan $30.5 \mathrm{~kW}$. Efesiensi kompor biomassa tipe downdraft system continue pada penelitian adalah sebesar $23,6 \%$.
\end{abstract}

Kata kunci : Burner, Reactor, Ass Box dan Sekam

\section{REDESIGN OF COMMUNICATION OF BIOMASS TYPE DOWNDRAFT SYSTEM CONTINUE USING RICE HUSBANDS}

\begin{abstract}
The ossification stove is one of the technologies for biomass for cooking purposes in the household sector. Biomass ossification is a process of thermal decomposition of organic materials through the provision of a number of heat with limited oxygen supply to produce synthesis gases consisting of $\mathrm{CO}, \mathrm{H} 2, \mathrm{CH} 4$ (hereinafter referred to as syn-gas) as the main product and a small amount of carbon and ash charcoal as a follow-up product. My main goal is to create technological innovations that are currently developing so that the results obtained are more effective and quality. The research method used in the research is the experimental method, beginning with observations in the field (observation) then from the literature study source then applied in one dimensional model with planning realized in one real form in the form of a downdraft type biomass stove system continue. Consecutive fuel consumption is obtained at $0.00012 ; 0.00028$; and $0,00050 \mathrm{~kg} / \mathrm{day}$. The total is operating time of the stove is $14 ; 16$ and 18 minutes Power input based on the results of the analysis of 0.00037 ; 0.00088; and $0.00154 \mathrm{~kW}$. Based on the analysis results, the lowest output power is $7.3 ; 17.1$ and $30.5 \mathrm{~kW}$. The efficiency of the downdraft system continuous biomass stove in the study was $23.6 \%$.
\end{abstract}

Key words : burner, reactor, ass box and husk 


\section{PENDAHULUAN}

Biomassa (Babu B. V, 2003) merupakan material biologis berupa tumbuhan dan hewan yang dapat diubah menjadi sumber energi. Berbagai jenis biomassa dari hasil sisa pengolahan bahan pertanian seperti sekam padi, tongkol jagung, ampas tebu, serbuk kayu, yang selama ini belum dimanfaatkan secara maksimal. Biomassa ini dapat digunakan sebagai bahan bakar alternatif pengganti minyak bumi yang cocok dikembangkan di Indonesia karena jumlahnya yang melimpah.

Di Indonesia khususnya di Provinsi Gorontalo memiliki tanaman padi yang sekali panen menghasilkan limbah pertanian yang sangat melimpah. Salah satu limbah pertanian tersebut adalah sekam padi. Kebiasaan yang sering dilakukan oleh petani adalah dengan melakukan pembakaran sekam padi. Hal inilah yang membawa dampak pada pwencemaran lingkungan, yang bersumber dari asap pembakaran sekam padi tersebut.

Kendala yang masih dihadapi antara lain adalah masih kurang lancarnya proses reaksi termokimia yang berlangsung di dalam reaktor tungku gasifikasi, sehingga kontinuitas proses gasifikasi belum optimal. Dari banyak percobaan yang sudah dilakukan oleh para akademisi, banyak faktor yang mempengaruhi kelancaran reaksi termokimia dalam proses gasifikasi pada tungku tersebut.

Berdasar latar belakang dan penelitian sebelumnya, Penulis akan merancang kompor biomassa tipe downdraft system continue dengan bahan bakar sekam padi dimanfaatkan menjadi sumber bahan bakar pengganti minyak tanah, gas elpiji, dan kayu bakar, serta sekam padi diolah menjadi pupuk organik yang ramah lingkungan.

\section{TINJAUAN PUSTAKA}

\section{Gasifikasi Biomassa}

Kompor gasifikasi (Belonio A. T, 2005) adalah salah satu teknologi pemanfaatan biomassa untuk keperluan memasak pada sektor rumah tangga. Gasifikasi biomassa merupakan suatu proses dekomposisi termal dari bahan-bahan organik melalui pemberian sejumlah panas dengan suplai oksigen terbatas untuk menghasilkan synthesis gases yang terdiri dari $\mathrm{CO}, \mathrm{H} 2, \mathrm{CH} 4$ (selanjutnya disebut dengan syn-gas) sebagai produk utama dan sejumlah kecil arang karbon dan abu sebagai produk ikutan. Gasifikasi pada dasarnya adalah alat yang memungkinkan mengubah bahan bakar padat menjadi bahan bakar gas oleh proses termokimia akibat oksidasi cepat. Proses ini melibatkan oksidasi partial dan temperatur tinggi, reaksi oksidasi dan reduksi diantara bahan bakar padat-udara.

Proses pembakaran yang terjadi menyebabkan reaksi termo-kimia yang menghasilkan $\mathrm{CO}, \mathrm{H} 2$, dan gas metana $(\mathrm{CH} 4)$. Selain itu, dalam proses ini juga dihasilkan uap air $(\mathrm{H} 2 \mathrm{O})$ dan karbon dioksida $(\mathrm{CO} 2)$ yang tidak terbakar.

Dalam penelitian (Wulandari, D, L.O Nelwan, A.H., 2014) menerangkan bahwa rancangan outlet reaktor yang terdiri dari sudut throat sangat mempengaruhi nilai kalor yang dihasilkan oleh tungku. Dalam analisis yang dihasilkan, diketahui bahwa desain outlet sudut desain sudut throat $70^{\circ}, 80^{\circ}, 90^{\circ}$ diukur dari garis yang tegak lurus dengan reaktor menunjukkan nilai kalor volume gas $\mathrm{CO}, \mathrm{H} 2$, dan $\mathrm{CH} 4$ secara berturut-turut adalah 14,49\%, 9,65\% dan 2,39\%.

Kajian dimensi tenggorokan ruang reduksi gasifier tipe downdraft untuk gasifikasi limbah tongkol jagung. (Purwantana B, Sunarto, Hasan, 2011) menyebutkan bahwa desain throat atau tenggorokan tungku dan tinggi ruang reduksi berpengaruh nyata terhadap nyala efektif tungku dan produksi gas metan. Waktu nyala efektif yang besar ditentukan oleh suhu reduksi yang tinggi dan stabil. Dengan suhu diatas $3500^{\circ} \mathrm{C}$ dan tinggi ruang reduksi $10 \mathrm{~cm}$ mampu memberikan kinerja gasifikasi optimal.

Perancangan dan uji-kinerja reaktor gasifikasi sekam padi skala kecil (Agung, 2013) menjelaskan bahwa pembuatan tungku gasifikasi skala kecil dengan dimensi diameter reaktor 13,97 $\mathrm{cm}$ dan tinggi reaktor $60 \mathrm{~cm}$ sudah mampu mengeluarkan lidah api pada menit ke 7 dari start up. Nyala api yang dihasilkan masih kurang stabil seperti yang diharapkan, karena masih kurang lancarnya proses gasifikasi. Terutama dibagian burner yang masih menyimpan endapan atau padatan sisa pembakaran.

\section{METODE PENELITIAN}

Metode penelitian yang digunakan dalam penelitian adalah metode eksperimen, diawali pengamatan dilapangan (observasi) kemudian dari sumber studi pustaka selanjutnya di aplikasikan dalam satu model dimensi dengan perencanaan yang diwujudkan dalam satu bentuk nyata berupa prototipe kompor biomassa tipe downdraft system continue. pembuatan dan perakitan alat di kerjakan di Labolatorium Mesin Umum dan Labolatorium 
Welding Program Studi Mesin dan Peralatan Pertanian Politeknik Gorontalo. Penelitian ini dilaksanakan pada bulan Nvember 2017 sampai bulan agustus 2018 .

\section{HASIL DAN PEMBAHASAN}

\section{Proses Pembuatan Kompor Biomassa Tipe Downdraft System Continue}

Pembuatan kompor biomassa tipe downdraft system continue dibagi menjadi 3 bagian diawali dari pembuatan rangka alat box ash, tabung silinder, dan burner. Setelah selesai lalu dipasang ke tiga bagian tersebut menjadi utuh, kompor biomassa ini memiliki tinggi total $96 \mathrm{~cm}$. Hasil atau bentuk dari kompor biomasa tipe downdraft system continue seperti ditunjukan pada Gambar 1. sebagai berikut.
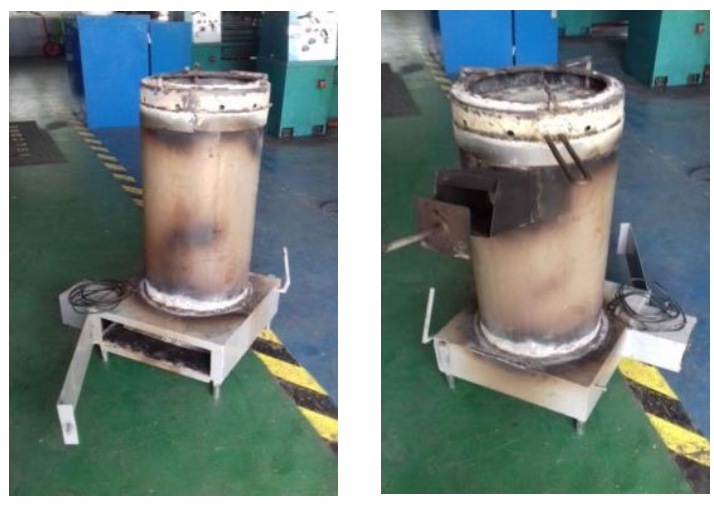

Gambar 1. Hasil Pembuatan Kompor Biomassa Tipe Downdraft System Continue

Gambar 4.1 menunjukkan hasil bentuk utuh kompor biomassa tipe downdraft system continue. Kompor biomassa ini memiliki corong input bahan bakar berkelanjutan dengan menggunakan system continue yang bisa dibuka tutup, dan box ash yang bisa dibuka tutup.

\section{Perancangan Struktural Kompor Biomassa}

Pengerjaan struktur kompor biomassa meliputi pengelasan, roll plat, penekukan plat, dan pemotongan plat. Pengerjaan struktur paling banyak memakan waktu yaitu dengan proses penyambungan atau teknik pengelasan. Bagianbagian komponen struktural ialah sebagai berikut:

a. Rangka alat

Rangka Alat dibuat menggunakan besi siku berukuran $30 \times 20 \mathrm{~mm}$ dengan ketebalan $1.5 \mathrm{~mm}$ berbahan dasar besi ST 37. Dapat dilihat pada Gambar 4.2 rangka box ash sebagai berikut.

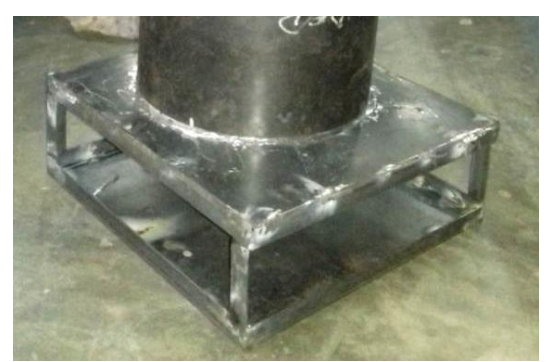

Gambar 2. Rangka Alat

b. Ash Box (Kotak Abu)

Kotak Abu dibuat menggunakan besi siku dan dilapisi plat Essel dengan tebal $1.6 \mathrm{~mm}$. Gambar 3 model box ash yang akan digunakan sebagai landasan kompor biomassa sebagai berikut.

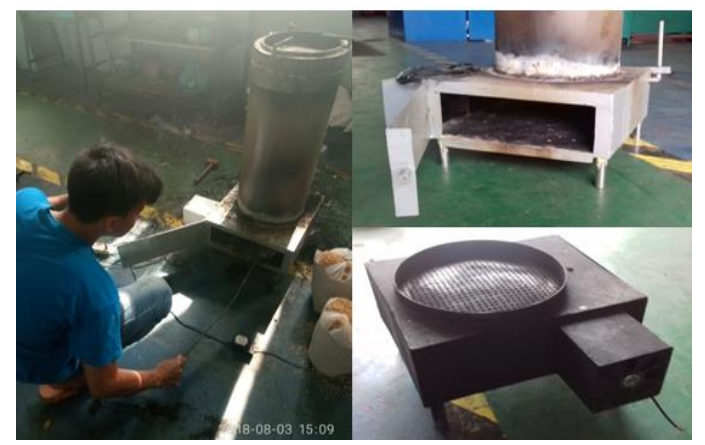

Gambar 3. Ash Box (Kotak Abu)

c. Saringan Udara

Saringan terbuat dari besi plat kalpanis dengan tebal $2 \mathrm{~mm}$, saringan udara berukuran $31 \times 31 \mathrm{~cm}$ membentuk kotak persegi, Jarak antara lubang berukuran $1 \times 1 \mathrm{~cm}$. saringan udara dapat dilihat pada Gambar 4 yaitu sebagai berikut.

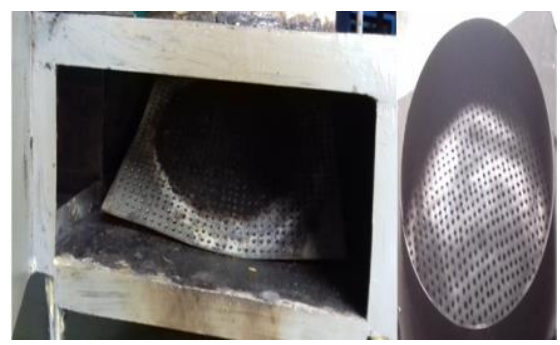

Gambar 4. Saringan Udara

\section{d. Tabung Silinder}

Tabung silinder yang dipakai mempunyai dua silinder yaitu silinder luar $\emptyset 30$ dan silinder dalam Ø25, silinder luar dibuat dari besi plat Essel dengan tebal $1.6 \mathrm{~mm}$ sedangkan silinder dalam menggunakan besi plat kalpanis dengan ukuran tebal $2 \mathrm{~mm}$, corong input berukuran $10 \times 10 \times 20$ $\mathrm{cm}$ berbentuk persegi panjang. Bentuk tabung 
silinder terlihat pada Gambar 5 yaitu sebagai berikut.

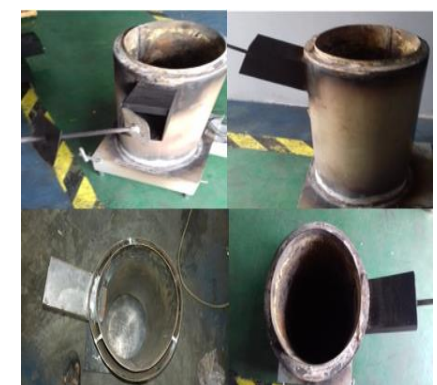

Gambar 5. Tabung Silinder

e. Burner (kepala kompor)

Burner terbuat dari besi plat kalpanis dengan tebal $2 \mathrm{~mm}$ yang berfungsi sebagai pengatur untuk keluarnya sumbu nyala api, burner berukuran $\varnothing 31$ dan Ø26 membentuk silinder, tinggi burner $15 \mathrm{~cm}$, burner memiliki lubang keluarnya api Jarak antara lubang berukuran $2 \mathrm{~cm}$. Burner bisa dilihat pada Gambar 6 yaitu sebagai berikut.

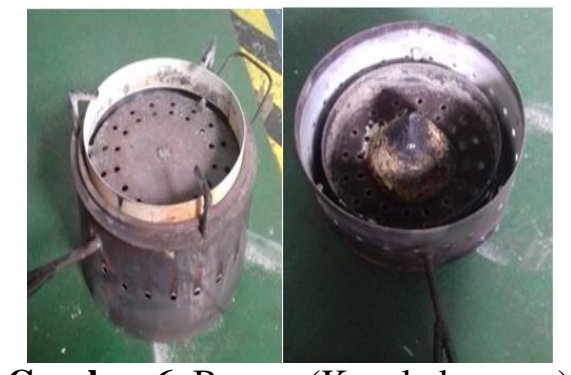

Gambar 6. Burner (Kepala kompor)

\section{f. Blower (kipas)}

Kipas blower yang digunakan pada kompor biomassa tipe downdraft system continue ini menggunakan tegangan AC $220 \mathrm{v} 0.14_{\mathrm{A}}$, blower yang digunakan dapat dilihat pada Gambar 7 sebagai berikut

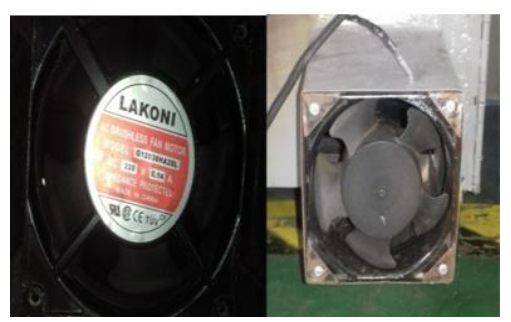

Gambar 7. Blower (kipas)

\section{Data Hasil Pengujian}

Eksperimen pengujian dan evaluasi performa kompor gasifikasi tipe downdraft system continue meliputi data waktu start-up, laju komsumsi bahan bakar (fuel consumption rate), analisis power input, efesiensi termal dan power output.
Tabel 1. Data hasil pengujian metode water boiling time (WBT)

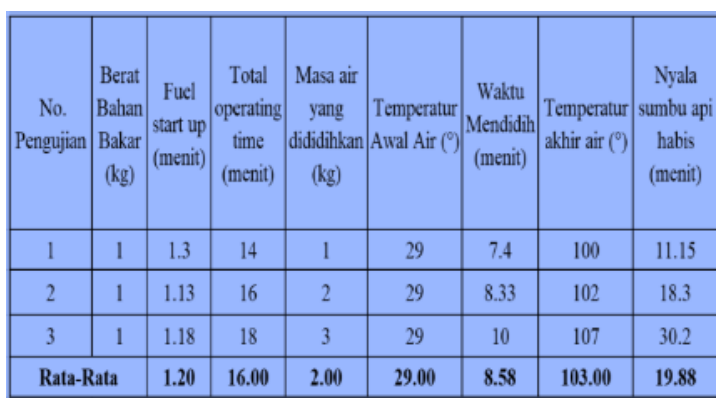

Tabel 1 menunjukkan data hasil pengujian menggunakan metode water boiling time (WBT). Percobaan dilakukan sebanyak tiga kali dengan jumlah bahan bakar yang sama yaitu $1 \mathrm{~kg}$. Berdasarkan data pengujian didapatkan hasil pengujian dengan $1 \mathrm{~kg}$ masa air yang dididihkan menunjukkan total operating time yang paling rendah yaitu 14 menit, temperature akhir yang dihasilkan juga lebih kecil dibanding lainnya yaitu sebesar $11.15^{\circ}$. Pada pengujian tersebut proses pendidihan $1 \mathrm{~kg}$ air berlangsung cepat yaitu terjadi pada menit ke 7.4. Hal ini dapat terjadi karena kompor terisi bahan bakar sekam padi yang mempunyai sifat pembakaran berkelanjutan sehingga nyala api lebih besar. Sedangkan percobaan ketiga dengan $3 \mathrm{~kg}$ masa air yang dididihkan menunjukkan total operating time yang paling tinggi yaitu 18 menit, temperature akhir yang dihasilkan juga lebih besar yaitu sebesar $30.02^{\circ}$. Pada pengujian tersebut proses pendidihan $3 \mathrm{~kg}$ air berlangsung agak lama yaitu terjadi pada menit ke 10. Hal ini dapat terjadi karena kompor masih terisi abu sekam padi yang mengendap akibatnya tekanan udarapun berkurang naik keatas sehingga temperature akhir lebih lama padam.

Proses pengujian kompor biomassa gasifikasi tipe downdraft system continue menggunakan bahan bakar sekam padi dapat ditunjukkan pada Gambar 8 sebagai berikut.

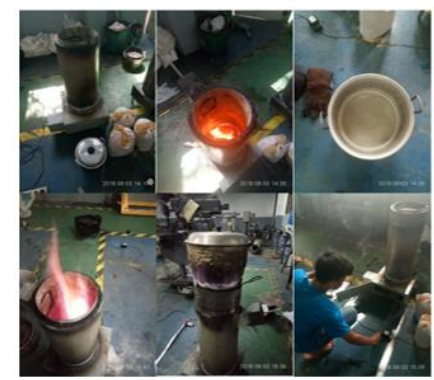

Gambar 8. Proses Uji Coba

Dari hasil Gambar 8 menunjukan bahwa proses uji coba meliputi menyiapkan alat yang akan digunakan, bahan bakar yang sudah terukur 
perkilo, dan jumlah air yang akan dididihkan. Setelah sudah selesai masukkan bahan bakar pada kompor lalu bakar menngunakan kertas dibantu sirami solar sedikit-demisedikit. Setelah sudah naik nyala apinya lalu dipasang burner kompor, setelah itu didihkan air sesuai takaran pengujian, setelah selesai pengujian lalu lakukan pembersian abu sekam pada box ash.

\section{Analisis Performa Kompor Biomassa Tipe Downdraft System Continue}

a. Hubungan Power input terhadap Power Output

Hubungan parameter PO dan Pi adalah Jumlah energi yang dibutuhkan yaitu mengacu pada jumlah panas yang dipasok. Ditentukan dengan mengetahui Qn sebagai berikut.

Dengan percobaan pertama :

$$
\begin{aligned}
& \mathrm{Qn}=\frac{\text { Mf } \times \text { Es }}{\mathrm{T}} \\
& \mathrm{Qn}=\frac{1 \times 72}{9.8} \\
& \mathrm{Qn}=7.3(\mathrm{kCal} / \mathrm{hr})
\end{aligned}
$$

Dengan percobaan kedua:

$$
\begin{aligned}
& \mathrm{Qn}=\frac{\text { Mf x Es }}{\mathrm{T}} \\
& \mathrm{Qn}=\frac{1 \times 72}{9.8} \\
& \mathrm{Qn}=7.3(\mathrm{kCal} / \mathrm{hr})
\end{aligned}
$$

Dengan percobaan ketiga :

$$
\begin{aligned}
& \mathrm{Qn}=\frac{\text { Mf } \times \mathrm{Es}}{\mathrm{T}} \\
& \mathrm{Qn}=\frac{3 \times 72}{7.1} \\
& \mathrm{Qn}=30.1(\mathrm{kCal} / \mathrm{hr})
\end{aligned}
$$

\section{b. Sensible Heat}

Sensible Heat adalah energi panas yang dibutuhkan untuk menaikkan suhu air yang diukur sebelum air mendidih dan sesudah mendidih.

Dengan percobaan pertama :

$$
\begin{aligned}
& \mathrm{SH}=\mathrm{Mw} \times \mathrm{Cp} \times(\mathrm{Tf}-\mathrm{Ti}) \\
& \mathrm{SH}=3 \times 1 \times 70 \\
& \mathrm{SH}=210
\end{aligned}
$$

Dengan percobaan kedua :

$$
\begin{aligned}
\mathrm{SH} & =\mathrm{Mw} \times \mathrm{Cp} \times(\mathrm{Tf}-\mathrm{Ti}) \\
\mathrm{SH} & =2 \times 1 \times 70 \\
\mathrm{SH} & =140 \\
\text { Dengan percobaan ketiga }: & \\
\mathrm{SH} & =\mathrm{Mw} \times \mathrm{Cp} \times(\mathrm{Tf}-\mathrm{Ti}) \\
\mathrm{SH} & =1 \times 1 \times 70 \\
\mathrm{SH} & =70
\end{aligned}
$$

\section{c. Latent Healt}

Latent Heat adalah jumlah energi yang digunakan untuk menguapkan air dengan menggunakan formula sebagai berikut.

Dengan percobaan pertama :

$$
\begin{aligned}
& \text { LH }=\text { We } \times \text { Hfg } \\
& \text { LH }=3 \times 540 \\
& \text { LH }=1620
\end{aligned}
$$

Dengan percobaan kedua :

$$
\begin{aligned}
& \mathrm{LH}=\text { We } \times \mathrm{Hfg} \\
& \mathrm{LH}=2 \times 540 \\
& \mathrm{LH}=1080
\end{aligned}
$$

Dengan percobaan ketiga :

$$
\begin{aligned}
& \text { LH }=\text { We } \times \text { Hfg } \\
& \text { LH }=1 \times 540 \\
& \text { LH }=540
\end{aligned}
$$

d. Laju Konsumsi Bahan Bakar Spesifik

Dengan percobaan pertama :

$$
\begin{aligned}
\mathrm{FCR} & =\frac{\mathrm{Qn}}{\text { HVF x nV }} \\
\mathrm{FCR} & =\frac{7.3}{2582.3 \times 23.6} \\
\mathrm{FCR} & =0.00012 \mathrm{~kg} / \mathrm{hr}
\end{aligned}
$$

Dengan percobaan kedua :

$$
\begin{aligned}
\mathrm{FCR} & =\frac{\mathrm{Qn}}{\text { HVF } \times \mathrm{nV}} \\
\mathrm{FCR} & =\frac{17.3}{2582.3 \times 23.6} \\
\mathrm{FCR} & =0.00028 \mathrm{~kg} / \mathrm{hr}
\end{aligned}
$$

Dengan percobaan ketiga :

$$
\begin{aligned}
\mathrm{FCR} & =\frac{\mathrm{Qn}}{\mathrm{HVF} \times \mathrm{nV}} \\
\mathrm{FCR} & =\frac{30.3}{2582.3 \times 23.6} \\
\mathrm{FCR} & =0.00050 \mathrm{~kg} / \mathrm{hr}
\end{aligned}
$$

e. Perhitungan efesiensi termal

Efesiensi termal adalah perbandingan antara nilai kalor yang diterima oleh air dengan nilai kalor yang terkandung dalam bahan bakar. Perhitungan efisiensi termal dilakukan dengan menggunakan persamaan umum yang biasa digunakan metode water boiling test (WBT) sebagai berikut.

Dengan percobaan pertama :

$$
\begin{aligned}
\mathrm{n} & =\frac{\mathrm{SH}+\mathrm{LH}}{\mathrm{HVF} \times \mathrm{WF}} \times 100 \\
\mathrm{n} & =\frac{210+1620}{2582.3 \times 3} \times 100 \\
\mathrm{n} & =23.6 \%
\end{aligned}
$$

Dengan percobaan kedua :

$$
\mathrm{n}=\frac{\mathrm{SH}+\mathrm{LH}}{\mathrm{HVF} \times \mathrm{WF}} \times 100
$$




$$
\begin{aligned}
& \mathrm{n}=\frac{140+1080}{2582.3 \times 2} \times 100 \\
& \mathrm{n}=23.6 \%
\end{aligned}
$$

Dengan percobaan ketiga :

$$
\begin{aligned}
& \mathrm{n}=\frac{\text { SH }+ \text { LH }}{\text { HVF } \times W F} \times 100 \\
& n=\frac{70+540}{2582.3 \times 1} \times 100 \\
& n=23.6 \%
\end{aligned}
$$

\section{f. Power Input}

Power Input adalah jumlah energi yang dipasok kedalam kompor berdasarkan bahan bakar yang digunakan.

Percobaan Pertama :

$$
\begin{aligned}
\mathrm{Pi} & =0.0012 \times \mathrm{FCR} \times \mathrm{HVF} \\
\mathrm{Pi} & =0.0012 \times 0.00012 \times 2582.3 \\
\mathrm{Pi} & =0.00037 \mathrm{~kW}
\end{aligned}
$$

Percobaan Kedua :

$$
\begin{aligned}
& \mathrm{Pi}=0.0012 \times \mathrm{FCR} \times \mathrm{HVF} \\
& \mathrm{Pi}=0.0012 \times 0.00028 \times 2582.3 \\
& \mathrm{Pi}=0.00088 \mathrm{~kW}
\end{aligned}
$$

Percobaan Ketiga :

$$
\begin{aligned}
& \mathrm{Pi}=0.0012 \times \mathrm{FCR} \times \mathrm{HVF} \\
& \mathrm{Pi}=0.0012 \times 0.00050 \times 2582.3 \\
& \mathrm{Pi}=0.00154 \mathrm{~kW}
\end{aligned}
$$

g. Power Output

Power output adalah jumlah energi yang dihasilkan oleh kompor untuk memasak.

Percobaan Pertama :

$$
\begin{aligned}
& \text { Po }=\text { FCR } \times \text { HVF } \times \eta \\
& P o=0.00012 \times 2582.3 \times 23.6 \\
& P o=7.3 \mathrm{~kW}
\end{aligned}
$$

Percobaan Kedua :

$$
\begin{aligned}
& \text { Po }=\text { FCR } \times \text { HVF } \times \eta \\
& \text { Po }=0.00028 \times 2582.3 \times 23.6 \\
& \text { Po }=17.1 \mathrm{~kW}
\end{aligned}
$$

Percobaan Ketiga :

$$
\begin{aligned}
& \text { Po }=\text { FCR } \times \text { HVF } \times \eta \\
& \text { Po }=0.00050 \times 2582.3 \times 23.6 \\
& P o=30.5 \mathrm{~kW}
\end{aligned}
$$

Dengan mengetahui performa atau kinerja kompor biomassa tipe downdraft system continue ialah dengan cara menghitung parameter power output, input, laju bakar, effesiensi termal telah didapatkan. Di tunjukkan pada gambar grafik dibawah ini sebagai berikut.

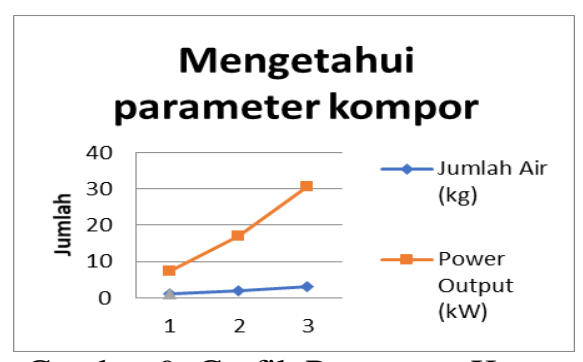

Gambar 9. Grafik Parameter Kompor

\section{PENUTUP}

\section{Kesimpulan}

Dari hasil pengujian dan analisis data pengujian kompor biomassa tipe downdraft system continue dengan 3 variasi ukuran masa air, dapat diambil kesimpulan sebagai berikut :

1 Ukuran kompor biomassa berdiameter luar 30 $\mathrm{cm}$, ruang bakar memiliki $\emptyset 25 \mathrm{~cm}$, tinggi total $96 \mathrm{~cm}$ serta Gap antara dinding luar dan ruang bakar sebesar $2.5 \mathrm{~cm}$ berisikan glashul memiliki corong isi ulang bahan bakar menjadikan kompor biomasa memiliki masa pembakaran lebih lama dan berkelanjutan.

2 Hasil analisis menunjukkan bahwa ukuran bahan bakar untuk masa air hanya dapat berpengaruh pada endapan abu bahan bakan menjadikan siklus pembakaran lebih lama.

3 Komsumsi bahan bahkar berturut-turut didapat sebesar 0.000120 .00028 ; dan $0.00050 \mathrm{~kg} / \mathrm{hr}$.

4 Total operating time dari kompor masingmasing sebesar 14; 16 dan 18 menit

5 Power input berdasarkan hasil analisis masingmasing sebesar $0.00037 ; 0.00088$; dan $0.00154 \mathrm{~kW}$.

6 Berdasarkan hasil analisis didapatkan power output terendah sebesar $7.3 ; 17.1$ dan 30.5 $\mathrm{kW}$.

7 Efesiensi kompor biomassa tipe downdraft system continue pada penelitian adalah sebesar $23,6 \%$. Disimpulkan bahwa efesiensi kompor biomassa ini lebih tinggi sedikit dibandingkan efesiensi kompor biomassa sebenlumnya.

\section{Saran}

Pembuatan kompor biomassa berkelanjutan atau yang akan meredesain kompor biomassa ini perlu memperhatikan tinggi total dari dari kompor biomassa agar dapat di kurangkan sehingga nyala efektif akan bertambah. Dan pada burner atau kepala kompor juga perlu di perhatikan saat pembuatan, burner haruslah memiliki ruang udara agar api bisa keluar pada lubang sumbu nyala api dan pembuatan sumber lubang sumbu nyala api haruslah berbentuk cembung agar nyala api merah kebiru-biruan bisa didapat. 


\section{DAFTAR PUSTAKA}

Agung, W. (2013). Perancangan dan Uji Kinerja Reaktor Gasifikasi Sekam Padi Skala Kecil.

Babu B. V, C. A. S. (2003). Modeling For Pyrolysis of Solid Particle: Kinetics and Heat Transfer Effects. Energy Conversion and Management, 44, 2251-2275.

Belonio A. T. (2005). Department of Agricultural Engineering and Environmental Managemen College of Agriculture Central Philippine University.
Purwantana B, Sunarto, Hasan, Y. (2011). Kajian dimensi tenggorokan ruang reduksi gasifier tipe downdraft untuk gasifikasi limbah tongkol jagung.

Wulandari, D, L.O Nelwan, A.H., T. (2014). Pengembangan Metode Pembekuan Vakum Untuk Produk pangan. 